\title{
New Hybrid Lead Iodides: From One-dimensional Chain to Two-dimensional Layered Perovskite Structure
}

Kecai Xiong, ${ }^{a, \#}$ Wei Liu, ${ }^{a}$ Simon J. Teat, ${ }^{b}$ Litao An, ${ }^{a}$ Hao Wang, ${ }^{a}$ Thomas J. Emge, ${ }^{a}$ Jing Li ${ }^{a} * *$

${ }^{a}$ Department of Chemistry and Chemical Biology, Rutgers University, 610 Taylor Road, Piscataway, New Jersey 08854, United States

${ }^{b}$ Advanced Light Source, Lawrence Berkeley National Laboratory, Berkeley California 94720, United States

*To whom correspondence should be addressed. E-mail: jingli@,rutgers.edu

\# Current Address: School of Chemistry and Chemical Engineering, Jiangsu Normal University, Xuzhou, Jiangsu 221116, China 


\begin{abstract}
:
Two new hybrid lead halides $\left(\mathrm{H}_{2} \mathrm{BDA}\right)\left[\mathrm{PbI}_{4}\right](\mathbf{1})\left(\mathrm{H}_{2} \mathrm{BDA}=1\right.$,4-butanediammonium dication $)$ and $(\mathrm{HNPEIM})\left[\mathrm{PbI}_{3}\right]$ (2) (HNPEIM = N-phenyl-ethanimidamidine cation) have been synthesized and structurally characterized. X-ray diffraction analyses reveal that compound $\mathbf{1}$ features a two-dimensional corner-sharing perovskite layer whereas compound 2 contains one-dimensional edge-sharing double chains. The N-phenyl-ethanimidamidine cation within compound 2 was generated in-situ under solvothermal conditions. The optical absorption spectra collected at room temperature suggest that both compounds are semiconductors having direct band gaps, with estimated values of 2.64 and $2.73 \mathrm{eV}$ for $\mathbf{1}$ and $\mathbf{2}$, respectively. Results from the density functional theory (DFT) calculations are consistent with the experimental data. Density of states (DOS) analysis reveals that in both compounds $\mathbf{1}$ and $\mathbf{2}$, the energy states in the valence band maximum region are iodine $5 \mathrm{p}$ atomic orbitals with a small contribution from lead $6 \mathrm{~s}$, while in the region of conduction band minimum, the major contributions are from the inorganic ( $\mathrm{Pb} 6 \mathrm{p}$ atomic orbitals) and organic components $(\mathrm{C}$ and $\mathrm{N} 2 \mathrm{p}$ atomic orbitals) in compound $\mathbf{1}$ and $\mathbf{2}$, respectively.
\end{abstract}

\title{
Keywords:
}

Inorganic-organic hybrid semiconductor / Lead halide / Crystal structure / Amidine / Band gap 


\section{Introduction}

In the past two decades, inorganic-organic hybrid semiconductors have been one of the focusing areas of materials development due to their potential utility in optoelectronic applications [1-2]. The physical and structural properties of these materials can be fine tuned by substituting or tailoring the organic ligands or by modulating the inorganic modules. One of well investigated hybrid families is based on lead halides, in which organic ligands are incorporated/inserted in the three dimensional inorganic parent structure to break it down to two, one, or zero dimensions. The lead halides family can be classified in four different classes [3-5]. The hybrid perovskites of the form $\mathrm{APbX}_{3}$ (where $\mathrm{A}$ is ammonium cation; $\mathrm{X}=\mathrm{Cl}, \mathrm{Br}, \mathrm{I}$ ) features a three-dimensional network, many of which absorb sun energy effectively and are promising for use in solar cells [3]. The $\mathrm{A}_{2}^{1} \mathrm{~A}_{\mathrm{n}-1}^{2} \mathrm{~Pb}_{\mathrm{n}} \mathrm{X}_{3 \mathrm{n}+1}$ and $\mathrm{A}_{2}^{1} \mathrm{~A}_{\mathrm{m}}{ }_{\mathrm{Sn}} \mathrm{Sn}_{\mathrm{m}} \mathrm{X}_{3 \mathrm{~m}+2}$ classes, which have the two-dimensional layered structures [4], can be structurally derived from the three-dimensional analogue by slicing along specific crystallographic planes and inserting organic amines between the slices. The interlayer separation and thickness of the inorganic layers can be controlled through the choice of organic cations. And some one-dimensional chain-like structures and zero-dimensional molecular compounds have also been reported [5]. Some selected examples are listed in Table 1. These organic-inorganic hybrid materials are unique in that they incorporate both the organic and inorganic components in a single crystal lattice, therefore giving rise to combined physical properties due to the individual components as well as new features that are not possible with either component alone. The inorganic components offer useful optoelectronic and magnetic properties, substantial mechanical hardness and heat resistance. The organic cations can greatly improve the strutural tunability, 
material processability and flexibility, to name a few advantages. The structural conformations and charge properties of the organic cations also play important roles in directing and tailoring the structure types of the resulting hybrid materials. Inspired by the previous success in pervoskite-type hybrd materials, we have recently focused on the reactions of 1,4-butanediammonium diiodide $\left(\mathrm{H}_{2} \mathrm{BDAI}_{2}\right)$ and benzeneammonium iodide (BZAI) with $\mathrm{PbI}_{2}$ for the construction of new hybrid lead halides. Herein, we report the solvothermal synthesis of two new members, $\left(\mathrm{H}_{2} \mathrm{BDA}\right)\left[\mathrm{PbI}_{4}\right]$ (1) $\left(\mathrm{H}_{2} \mathrm{BDA}=1\right.$,4-butanediammonium dication $)$ and (HNPEIM) $\left[\mathrm{PbI}_{3}\right]$ (2) (HNPEIM = N-phenyl-ethanimidamidine cation), their structure characterization by both single crystal and powder X-ray diffraction methods, as well as their thermal and optical properties.

Table 1. Selected list of hybrid lead/tin halide compounds.

\begin{tabular}{|l|l|l|l|}
\hline Dimensionality & Hybrid Lead/Tin Halide & Chemical Formula & Reference \\
\hline $3 \mathrm{D}$ & $\mathrm{MAPbI}_{3}$ & $\mathrm{APbX}$ & 3 \\
\hline $2 \mathrm{D}$-monolayer & $(\mathrm{N}-\mathrm{MPDA})\left[\mathrm{PbBr}_{4}\right]$ & $\mathrm{BPbX}$ & 3 \\
\hline 2D-bilayer & {$\left[\mathrm{NH}_{2} \mathrm{C}(\mathrm{l})=\mathrm{NH}_{2}\right]_{2}\left(\mathrm{CH}_{3} \mathrm{NH}_{3}\right)_{2} \mathrm{Sn}_{2} \mathrm{I}_{8}$} & $\mathrm{~A}_{2}{ }_{2} \mathrm{~A}_{\mathrm{m}} \mathrm{Sn}_{\mathrm{m}} \mathrm{X}_{3 \mathrm{~m}+2}(\mathrm{~m}=2)$ & $4 \mathrm{~b}$ \\
\hline 2D-trilayer & $(\mathrm{MA})_{2}(\mathrm{PEA})_{2}\left[\mathrm{~Pb}_{3} \mathrm{I}_{10}\right]$ & $\mathrm{A}_{2}{ }_{2} \mathrm{~A}_{\mathrm{n}-1} \mathrm{~Pb}_{\mathrm{n}} \mathrm{X}_{3 \mathrm{n}+1}(\mathrm{n}=3)$ & $4 \mathrm{c}$ \\
\hline $1 \mathrm{D}-$ chain & {$\left[\left((\mathrm{R})-\mathrm{C}_{8} \mathrm{H}_{12} \mathrm{~N}\right) \mathrm{PbI}_{3}\right]$} & $\mathrm{APbX}_{3}$ & $5 \mathrm{a}$ \\
\hline $1 \mathrm{D}$-double-chain & $\left.\left[(\mathrm{MPL}-\mathrm{H})_{6} \mathrm{I}_{3}\right\}\left(\mathrm{Pb}_{2} \mathrm{I}_{9}\right)\right]$ & $\mathrm{A}_{6} \mathrm{~Pb}_{2} \mathrm{X}_{9} \mathrm{C}$ & $5 \mathrm{~b}$ \\
\hline 0D & $(\mathrm{NHAr})_{2} \mathrm{~Pb}_{2} \mathrm{I}_{2} \cdot 1.5 \mathrm{C}_{6} \mathrm{H}_{5} \mathrm{CH}_{3}$ & $\mathrm{~A}_{2} \mathrm{~Pb}_{2} \mathrm{X}_{2}$ & $5 \mathrm{c}$ \\
\hline
\end{tabular}

$\mathrm{A}=$ ammonium cation; $\mathrm{B}=$ diammonium dication; $\mathrm{C}=$ anion;

$\mathrm{MA}=$ methylammonium cation; $\mathrm{MPL}=$ morpholine;

$\mathrm{N}-\mathrm{MPDA}=\mathrm{N}^{1}$-methylpropane-1,3-diammonium dication;

PEA = phenethyl ammonium cation; (R)- $\mathrm{C}_{8} \mathrm{H}_{12} \mathrm{~N}=\mathrm{C}_{6} \mathrm{H}_{5} \mathrm{CH}\left(\mathrm{CH}_{3}\right) \mathrm{NH}_{3}{ }^{+}$. 


\section{Experimental Section}

\subsection{Materials and Measurements}

All chemicals are of reagent-grade quality and obtained from commercial sources and used without further purification. Lead(II) iodide (98.5\%, Alfa Aesar), hydriodic acid (57\%, w/w, Alfa Aesar), 1,4-butanediamine (98\%, Alfa Aesar), aniline (99\%, Alfa Aesar).

Powder X-ray diffraction (PXRD) analyses were carried out on a Rigaku Ultima-IV automated diffraction system using $\mathrm{Cu} \mathrm{K \alpha}$ radiation $(\lambda=1.5406 \AA)$. The data were collected at room temperature in a $2 \theta$ range of 3-50 degree with a scan speed of 1 degree/min. The operating power was $40 \mathrm{kV} / 40 \mathrm{~mA}$.

UV-Vis diffuse reflectance spectra were measured at room temperature on a Shimadzu UV-3600 UV/VIS/NIR spectrometer. The reflectance data were converted to Kubelka-Munk function, $\alpha / \mathrm{S}=(1-\mathrm{R})^{2} / 2 \mathrm{R}(\alpha$ is absorption coefficient, $\mathrm{S}$ is scattering coefficient and $\mathrm{R}$ is reflectance), and used to estimate the bandgap. Samples for reflectance measurements were prepared by evenly distributing ground powder sample between two quartz slides.

\subsection{Syntheses of $\mathrm{H}_{2} \mathrm{BDAI}_{2}$ and $\mathrm{BZAI}$}

1,4-butanediammonium diiodide $\left(\mathrm{H}_{2} \mathrm{BDAI}_{2}\right)$ and benzeneammonium iodide (BZAI) were prepared according to a method similar to that reported for the synthesis of methyammonium iodide [6]. 1,4-butanediammonium diiodide $\left(\mathrm{H}_{2} \mathrm{BDAI}_{2}\right)$ was synthesized by reacting $10 \mathrm{~mL}$ of 1,4-butanediamine (98\%, Alfa Aesar) and $33.0 \mathrm{~mL}$ of hydroiodic acid (57 wt\% in water, Alfa Aesar) in a $100 \mathrm{~mL}$ round-bottom flask at $0{ }^{\circ} \mathrm{C}$ for $6 \mathrm{~h}$ with stirring. The precipitate was recovered by putting the solution on a rotary evaporator and carefully removing the solvents at $50{ }^{\circ} \mathrm{C}$. The yellow powder was washed with diethyl ether by stirring the solution for $30 \mathrm{~min}$. 
After filtration, the yellow solid was collected and dried at $60{ }^{\circ} \mathrm{C}$ in a vacuum oven for $24 \mathrm{~h}$. Benzeneammonium iodide (BZAI) was synthesized by reacting $10.0 \mathrm{~mL}$ of aniline $(99 \%$, Alfa Aesar) and $18.0 \mathrm{~mL}$ of hydroiodic acid (57 wt\% in water, Alfa Aesar) in a $50 \mathrm{~mL}$ round-bottom flask at $0{ }^{\circ} \mathrm{C}$ for $6 \mathrm{~h}$ with stirring. The precipitate was recovered by putting the solution on a rotary evaporator and carefully removing the solvents at $50{ }^{\circ} \mathrm{C}$. The white powder was washed with diethyl ether by stirring the solution for $30 \mathrm{~min}$. After filtration, the white solid was collected and dried at $60{ }^{\circ} \mathrm{C}$ in a vacuum oven for $24 \mathrm{~h}$.

\subsection{Syntheses of Compounds 1-2}

Compound 1: Hydriodic acid $(57 \% ; 1.0 \mathrm{~mL})$ was added to the mixture of $\mathrm{PbI}_{2}(46 \mathrm{mg}, 0.10$ mmol) and 1,4-butanediammonium diiodide (34 $\mathrm{mg}, 0.10 \mathrm{mmol})$ at room temperature in a heavy-walled Pyrex tube. The reaction mixture was sonicated for 5 min to disperse the mixture. The tube was frozen under liquid nitrogen for 10 min before sealed under vacuum and placed inside an oven at $120{ }^{\circ} \mathrm{C}$ for 7 days. Yellow single crystals of 1 were obtained in $63 \%$ yield based on $\mathrm{PbI}_{2}$.

Compound 2: Acetonitrile (1.0 mL) was added to the mixture of $\mathrm{PbI}_{2}(46 \mathrm{mg}, 0.10 \mathrm{mmol})$ and benzeneammonium iodide $(22 \mathrm{mg}, 0.10 \mathrm{mmol})$ at room temperature in a heavy-walled Pyrex tube. The reaction mixture was sonicated for $5 \mathrm{~min}$ to disperse the mixture. The tube was frozen under liquid nitrogen for $10 \mathrm{~min}$. And then it was sealed under vacuum, and placed inside an oven at $120{ }^{\circ} \mathrm{C}$ for 7 days. Yellow single crystals of 2 were obtained in $45 \%$ yield based on $\mathrm{PbI}_{2}$.

\subsection{Single Crystal X-ray Data Collection and Structure Determination}


Single crystal synchrotron X-ray diffraction data of compounds $\mathbf{1}$ and $\mathbf{2}$ were collected at 100 $\mathrm{K}$ on a D8 goniostat equipped with a Bruker PHOTON100 CMOS detector on beamline 11.3.1 at the Advanced Light Source (ALS) in Lawrence Berkeley National Laboratory, using synchrotron radiation tuned to $\lambda=0.7749 \AA$. Data were also collected for compound $\mathbf{1}$ at room temperature $(298 \mathrm{~K})$ on the same beamline. The structures were solved by direct methods and refined by full-matrix least-squares on F2 using the Bruker SHELXTL package [7]. All non-hydrogen atoms were refined anisotropically. The organic hydrogen atoms were located at geometrically calculated positions and refined using a riding model. The low temperature structures were deposited in the Cambridge Structural Database (CSD), with CCDC-1053651 (1) and -1053652 (2). Details of the crystal data are summarized in Tables S1-S2.

\section{Results and Discussion}

\subsection{Crystal Structures and Phase Purity}

Analysis using the single crystal data collected at $100 \mathrm{~K}$ shows that compound $\mathbf{1}$ crystallizes

in the triclinic space group $P \overline{1}$, with the $2 \mathrm{D}$ layered structure feature of lead-iodine perovskite. In the asymmetric unit (Fig. 1a), there are two crystallographically distinct half lead ions, four different iodine anions, and one 1,4-butanediammonium dication. As shown in the figure, both lead ions are six-coordinated in an octahedral geometry. Every octahedron is connected by four neighboring ones via four iodine anions by corner sharing, forming a $2 \mathrm{D}$ perovskite layer (Fig. 2), very similar to the 2D perovskite layer in (N-MPDA) $\left[\mathrm{PbBr}_{4}\right][4 \mathrm{a}]$. The complicated interchain hydrogen bonding fertilizes its formation and stabilization (Fig. 
3). The $\mathrm{N}^{\cdots} \mathrm{I}$ distances range from $3.542(4)$ to $3.646(2) \AA$, which are comparable with those reported in the literature [5a, 8]. Compound $\mathbf{1}$ underwent a structural phase transition when temperature was raised from 100 to $298 \mathrm{~K}$. The structure changed from a triclinic cell at 100 $\mathrm{K}$ to a C-centered monoclinic cell at $298 \mathrm{~K}$. The monoclinic cell can be reduced to a primitive cell $\left(8.465 \AA, 8.867 \AA, 11.345 \AA, 77.34^{\circ}, 68.09^{\circ}, 90.00^{\circ}\right)$ which is very similar to the unit cell of $100 \mathrm{~K}$ (see Tables S1 and S2).

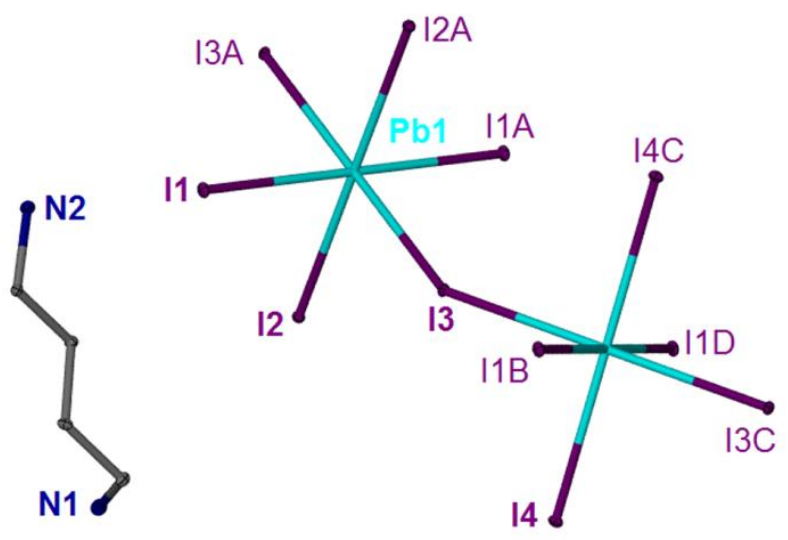

Fig. 1. The asymmetric unit of compound 1 with the displacement ellipsoids at the $30 \%$ probability level (symmetry codes: A -x, 1-y, 2-z; B 1-x, 1-y, 2-z; C -x, 2-y, 2-z; D $x, 1+y, z$.). Hydrogen atoms are omitted for clarity.

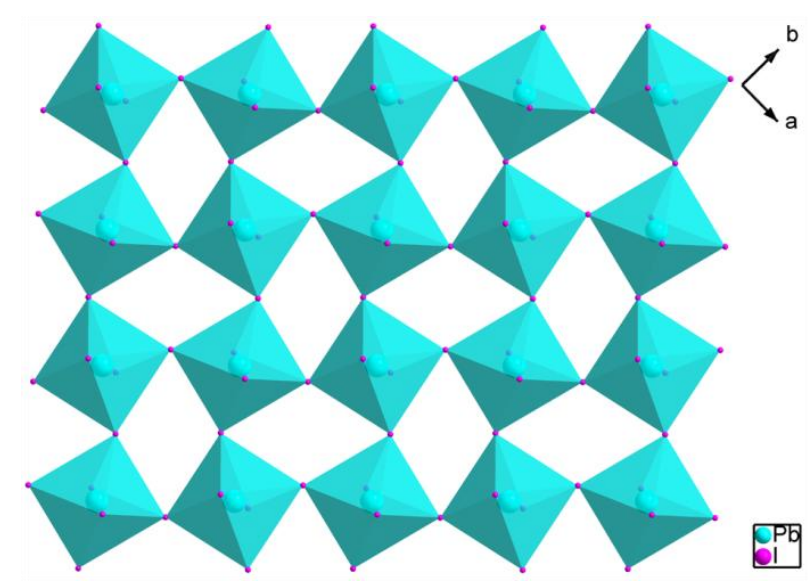

Fig. 2. The 2D perovskite layer within compound 1. 


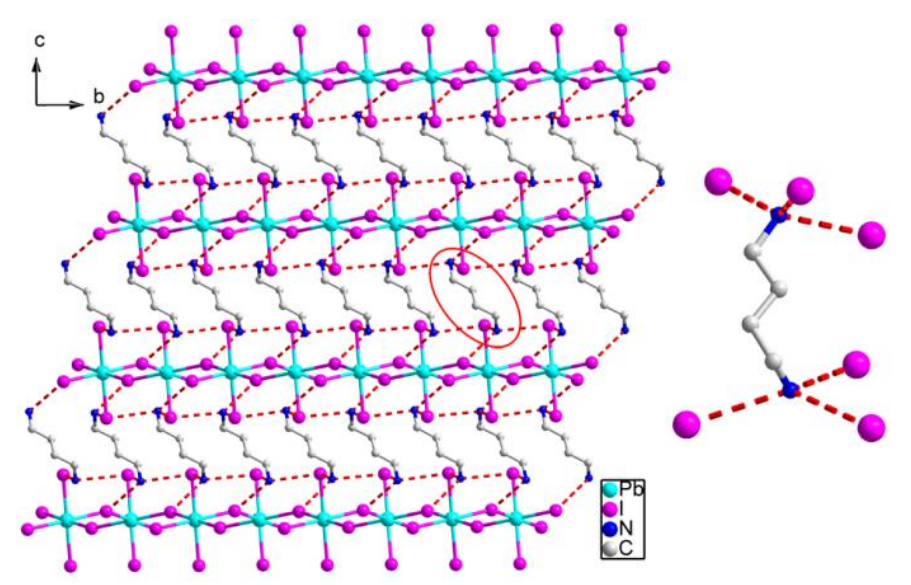

Fig. 3. Hydrogen bonding (dashed red lines) within compound 1 (right: hydrogen bonds for each 1,4-butanediammonium dication).

Compound 2 was obtained under similar conditions from a reaction of $\mathrm{PbI}_{2}$ and benzeneammonium iodide in acetonitrile rather than hydriodic acid. The reaction led to the formation of $\mathrm{N}$-phenyl-ethanimidamide cation (Scheme 1). The single-crystal X-ray diffraction shows that compound 2 crystallizes in the monoclinic system with $P 2_{1} / \mathrm{c}$ space group. The asymmetric unit of $\mathbf{2}$ consists of one crystallographically distinct Nphenyl-ethanimidamide cation, three iodine anions and one lead ion (Fig. 4). The latter is six-coordinated in a distorted octahedral geometry. Each octahedron is connected to two neighboring octahedra by sharing with four iodine anions, giving rise to an edge-sharing lead-iodine chain. Two of these 1D chains are further connected via edge-sharing of three iodine anions for each octahedron (Fig. 5), resulting in a 1D double-chain [1e]. It should be noted that this double-chain is formed by each octahedron edge-sharing with four neighboring octahedral units, which is very different from reported corner-sharing double-chain structures. [5b] In fact, the octahedra are corner-sharing in most hybrid lead halide structures [3-4]. The 
lead iodine double-chains in $\mathbf{2}$ are further connected through the hydrogen bonding interactions between the N-phenyl-ethanimidamidine cations and iodine anions (Fig. 6). The $\mathrm{N}^{\cdots} \mathrm{I}$ distances range from $3.566(9)$ to $3.689(8) \AA$, similar to those in compound $\mathbf{1}$, as well as literature values $[5 \mathrm{a}, 8] . \quad$ It is interesting to note that compound 2 with the chemical formula of $\mathrm{APbI}_{3}$ features the one-dimensional structure rather than the three-dimensional perovskite structure [3]. Furthermore, the N-phenyl-ethanimidamidine cation within compound 2 was formed in-situ under solvothermal conditions. Recently, attempts to synthesize acentric metal-organic complexes by in-situ formation of ligands have generated some success [9]. The hydrothermal/solvothermal reactions are often quite complicated and may involve in situ formation of ligands. Often, the products produced under hydrothermal conditions cannot be obtained by direct mixing of solutions of metal ions and ligands. This is indeed the case of $\mathrm{N}$ phenyl-ethanimidamidine cation. The amidines are typically synthesized in the presence of aluminum chloride as catalyzer [10]. This work represents an example of formation of amidine without the need of aluminum chloride.

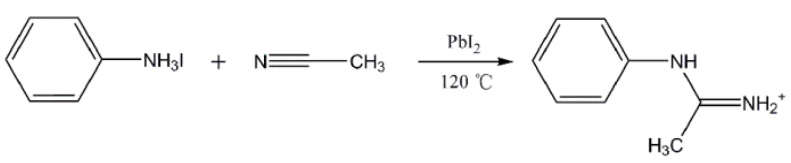

Scheme 1. In-situ formation of N-phenyl-ethanimidamidine cation.

The phase purity of compounds $\mathbf{1}$ and $\mathbf{2}$ are confirmed by powder X-ray diffraction analysis (PXRD, Fig. S1). The peak positions of observed PXRD patterns are generally in good agreement with those simulated from single crystal X-ray data, indicating that relatively pure phases are obtained. The slight mismatch between the measured and simulated PXRD 
patterns of compound $\mathbf{1}$ can be accounted for by the small structural changes due to the different experimental temperatures.
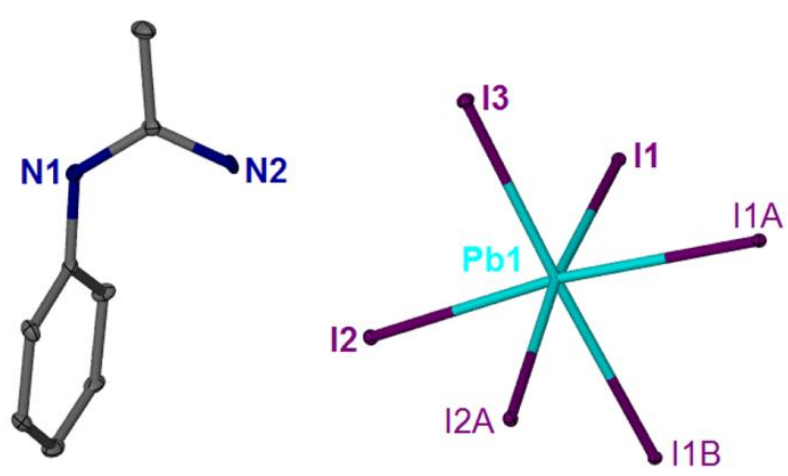

Fig. 4. The asymmetric unit of compound 2 with the displacement ellipsoids at the $30 \%$ probability level (symmetry codes: A $x-1, y, z$; B 1-x, 1-y, 1-z.). Hydrogen atoms are omitted for clarity.

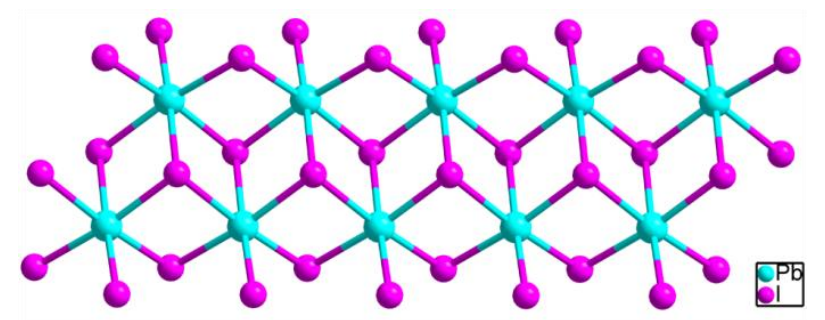

Fig. 5. 1D lead iodine chain within compound 2. 


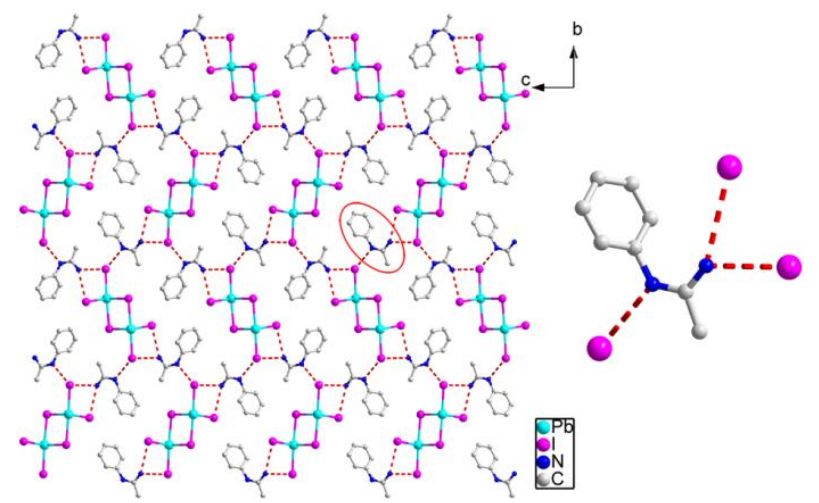

Fig. 6. Hydrogen bonding (dashed red lines) within compound 2 (right: hydrogen bonds for each N-phenyl-ethanimidamidine cation) .

\subsection{Optical Absorption Study and DFT Calculations}

The optical absorption spectra for compounds $\mathbf{1}$ and $\mathbf{2}$ were recorded at room temperature and converted to Kubelka-Monk function, as shown in Fig. 8. The absorption edges for compounds 1 and 2 were found to be 2.64 and $2.73 \mathrm{eV}$, respectively. Both cmpounds appear to be semiconductors with direct band gap.

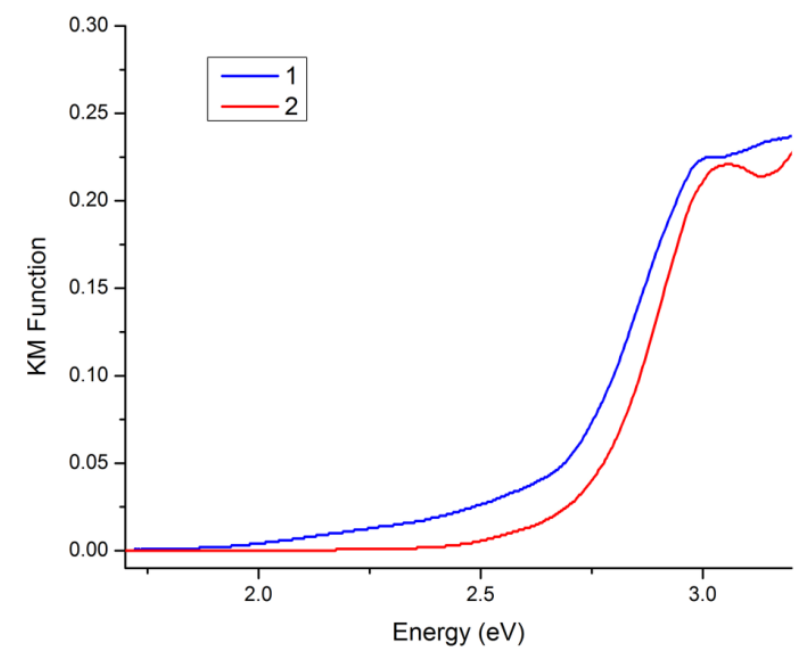

Fig. 7. Optical absorption spectra for compounds $\mathbf{1}$ (blue) and $\mathbf{2}$ (red). The estimated optical band gaps are 2.64 and $2.73 \mathrm{eV}$ for compound $\mathbf{1}$ and $\mathbf{2}$, respectively. 
First-principle calculations of the band structure (BS) and density of states (DOS) of compounds 1 and $\mathbf{2}$ were carried out using the CASTEP code implemented in the Material studio 4.4 package, and the results are plotted in Figure 8 [11]. Generalized gradient approximations (GGA) with Perdew-Burke-Ernzerhof (PBE) exchange-correlation functional (xc) were used in all calculations. The Monkhorst-Pack scheme k-point grid sampling was set at $1 \times 1 \times 1$. The plane-wave basis set energy cutoff was set at $10.0 \mathrm{eV}$, ultrasoft pseudopotentials were used for all chemical elements and the total energy tolerance was set to be $1 \times 10^{-5} \mathrm{eV} /$ atom.

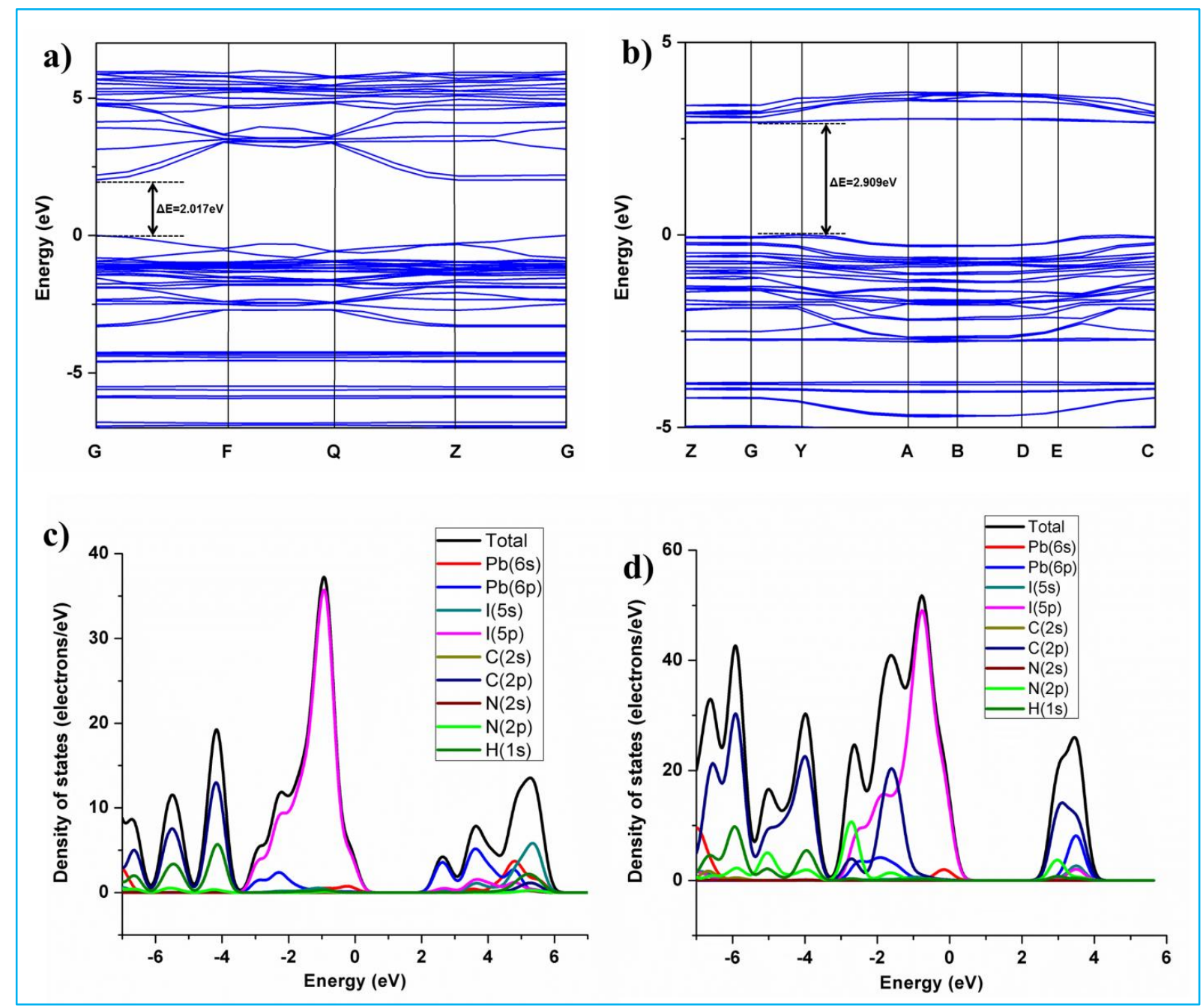

Fig. 8. Calculated band structure for (a) 1 and (b) 2. Total and projected DOS for (c) 1 and (d) 2. 
Calculated band structure of $\mathbf{1}$ shows a direct band gap of $2.017 \mathrm{eV}$ at $\mathrm{G}$ point in the reciprocal space, while $\mathbf{2}$ has a direct band gap of $2.909 \mathrm{eV}$ at Y point. Compounds $\mathbf{1}$ and $\mathbf{2}$ demonstrate similarities and differences in the atomic state distributions as shown in their density of states plots. In both compounds, the main atomic states found in the region of valence band (VB) maximum are iodine 5p orbitals, with a small contribution from lead $6 \mathrm{~s}$. These results are in general agreements with previously reported calculations [12]. However, for compound $\mathbf{1}$, the conduction band $(\mathrm{CB})$ minimum region is populated predominately by the $\mathrm{Pb} 6 \mathrm{p}$, with secondary contributions from I 5s and 5p orbitals. For compounds 2 , the $\mathrm{CB}$ is relatively narrow, and its minimum region is composed primarily of $\mathrm{C} 2 \mathrm{p}$ and $\mathrm{N} 2 \mathrm{p}$ orbitals. The distinct difference in the CBM composition of the two compounds is due to the presence of phenyl ring in compound 2 . The C $2 \mathrm{p} \pi$ orbitals contribute largely to the LUMO of the HNPEIM cation, and consequently to the VBM of compound 2, which are absent in compound 1 . These observations indicate that the inorganic component $(\mathrm{Pb}, \mathrm{I})$ dominates the VB maximum region in both compounds, whereas in the region of $\mathrm{CB}$ minimum, the major contributions are from the inorganic and organic components in compound $\mathbf{1}$ and $\mathbf{2}$, respectively.

\section{Conclusion}

In summary, two new hybrid lead iodides based on 1,4-butanediammonium diiodide $\left(\mathrm{H}_{2} \mathrm{BDAI}_{2}\right) /$ benzeneammonium iodide (BZAI) and lead iodide have been synthesized and structurally characterized. Compound $\mathbf{1}$ features 2D lead-iodine perovskite layers which are 
stabilized by interlayer hydrogen bonding and ionic bonding. Compound 2 contains fused lead-iodine double chains that are hydrogen-bonded with N-phenyl-ethanimidamide cations formed in-situ during the synthesis. In both cases, hydrogen bonding plays an important role in the formation and stabilization of the compounds. Both compounds have direct and relatively low and bandgaps whose values were estimated from the experimental optical absorption measurements and DFT calcualtions. While the atomic states populated in their VB maximum region are mainly from the inorganic elements $(\mathrm{Pb}, \mathrm{I})$, the composition in their $\mathrm{CB}$ minimum is very different, with atomic states of inorganic $(\mathrm{Pb}, \mathrm{I})$ and organic $(\mathrm{C}$ and $\mathrm{N})$ elements for compound $\mathbf{1}$ and $\mathbf{2}$, respectively.

\section{Supporting Information Available}

Single crystal X-ray crystallographic data for compounds $\mathbf{1}$ and $\mathbf{2}$ have been deposited at the Cambridge Crystallographic Data Center, CCDC 1053651, and 1053652. These data can be obtained free of charge at http://www.ccdc.cam.ac.uk/conts/retrieving.html (or from the Cambridge Crystallographic Data Center, 12 Union Road, Cambridge CB2 1EZ, UK; fax: (+44) 1223-336-033; e-mail: deposit@ccdc.cam.ac.uk).

\section{Acknowledgments}

We are grateful to the financial support from the National Science Foundation (DMR-1206700 and DMR-1507210). The Advanced Light Source is supported by the Director, Office of Science, Office of Basic Energy Sciences, of the U.S. Department of Energy under Contract No. DE-AC02-05CH11231. 


\section{References}

[1] (a) D. B. Mitzi, C. A. Feild, W. T. A. Harrison, A. M. Guloy, Nature 369(1994)467-469;

(b) F. Hao, C. C. Stoumpos, R. P. H. Chang, M. G. Kanatzidis, J. Am. Chem. Soc. 136(2014)8094-8099;

(c) B. V. Lotsch, Angew. Chem. Int. Ed. 53(2014)635-637;

(d) E. R. Dohner, A. Jaffe, L. R. Bradshaw, H. I. Karunadasa, J. Am. Chem. Soc. 136(2014)13154-13157;

(e) G. E. Wang, G. Xu, M. S. Wang, J. Sun, Z. N. Xu, G. C. Guo, J. S. Huang, J. Mater. Chem. 22(2012)16742-16744.

[2] (a) X. Y. Huang, J. Li, Y. Zhang, A. Mascarenhas, J. Am. Chem. Soc. 125(2003)7049-7055;

(b) X. Y. Huang, J. Li, J. Am. Chem. Soc. 129(2007)3157-3162;

(c) W. Ki, J. Li, J. Am. Chem. Soc. 130(2008)8114-8115;

(d) M. Roushan, X. Zhang, J. Li, Angew. Chem. Int. Ed. 51(2012)436-439;

(e) J. Li, W. H. Bi, W. Ki, X. Y. Huang, S. Reddy, J. Am. Chem. Soc. 129(2007)14140-14141;

(f) X. Y. Huang, M. Roushan, T. J. Emge, W. H. Bi, S. Thiagarajan, J. H. Cheng, R. G. Yang, J. Li, Angew. Chem. Int. Ed. 48(2009)7871-7874;

(g) X. Zhang, M. Hejazi, S. J. Thiagarajan, W. R. Woerner, D. Banerjee, T. J. Emge, W. Q. Xu, S. J. Teat, Q. H. Gong, A. Safari, R. G. Yang, J. B. Parise, J. Li, J. Am. Chem. Soc. 135(2013)17401-17407; 
(h) X. Zhang, W. Liu, G. Z. Wei, D. Banerjee, Z. C. Hu, J. Li, J. Am. Chem. Soc. 136(2014)14230-14236. [3] (a) F. Hao, C. C. Stoumpos, D. H. Cao, R. P. H. Chang, M. G. Kanatzidis, Nature Photonics 8(2014)489-494;

(b) T. Baikie, Y. N. Fang, J. M. Kadro, M. Schreyer, F. X. Wei, S. G. Mhaisalkar, M. Graetzel, T. J. White, J. Mater. Chem. A 1(2013)5628-5641;

(c) M. M. Lee, J. Teuscher, T. Miyasaka, T. N. Murakami, H. J. Snaith, Science $338(2012) 643-647$.

[4] (a) E. R. Dohner, E. T. Hoke, H. I. Karunadasa, J. Am. Chem. Soc. 136(2014)1718-1721;(b)

C. C. Tsuei, A. Gupta, G. Trafas, D. Mitzi, Science 263(1994)1259-1261;

(c) C. Smith, E. T. Hoke, D. Solis-Ibarra, M. D. McGehee, H. I. Karunadasa, Angew. Chem. Int. Ed. 53(2014)11232-11235.

[5] (a) D. G. Billing, A. Lemmerer, CrystEngComm 8(2006)686-695;

(b) H. H. Li, Z. R. Chen, L. C. Cheng, J. B. Liu, X. B. Chen, J. Q. Li, Cryst. Growth Des. 8(2008)4355-4358;

(c) L. A. M. Harris, E. C. Y. Tam, M. P. Coles, J. R. Fulton, Dalton Trans. 43(2014)13803-13814.

[6] C. C. Stoumpos, C. D. Malliakas, M. G. Kanatzidis, Inorg. Chem. 52(2013)9019-9038.

[7] (a) G. M. Sheldrick, SHELXS-97, Program for the Solution of Crystal Structures: University of Göttingen, Germany, 1997;

(b) G. M. Sheldrick, SHELXL-97, Program for the Refinement of Crystal Structures: University of Göttingen, Germany, 1997. 
[8] (a) H. R. Khavasi, M. Hosseini, A. A. Tehrani, S. Naderi, CrystEngComm 16(2014)4546-4553;

(b) A. Lemmerer,D. G. Billing, CrystEngComm 14(2012)1954-1966.

[9] (a) R. G. Xiong, X. Xue, H. Zhao, X. Z. You, B. F. Abrahams, Z. L. Xue, Angew. Chem. Int. Ed. 41(2002)3800-3803;

(b) K. C. Xiong, F. L. Jiang, Y. L. Gai, Z. Z. He, D. Q. Yuan, L. Chen, K. Z. Su, M. C. Hong, Cryst. Growth Des. 12(2012)3335-3341.

[10] (a) K. Maheswari, N. M. Rajendran, J. Meyer, N. D. Reddy, Organometallics 29(2010)3799-3807;

(b) D. Zhao, J. Hu, N. Wu, X. Huang, X. Qin, J. Lan, J. You, Org. Lett. 13(2011)6516-6519;

(c) J. Huang, Y. He, Y. Wang, Q. Zhu, Chem. Eur. J. 18(2012)13964-13967.

[11] S. J. Clark, M. D. Segall, C. J. Pickard, P. J. Hasnip, M. J. Probert, K. Refson, M. C. Payne, Zeitschrift Fur Kristallographie 220(2005)567-570.

[12] J. Brgoch, A. J. Lehner, M. Chabinyc, R. Seshadri, J. Phys. Chem. C. 18(2014)27721-27727. 


\section{New Hybrid Lead Iodides: From One-dimensional Chain to Two- dimensional Layered Perovskite Structure}

Kecai Xiong, ${ }^{a, \sharp}$ Wei Liu, ${ }^{a}$ Simon J. Teat,${ }^{b}$ Litao An,${ }^{a}$ Hao Wang, ${ }^{a}$ Thomas J. Emge,${ }^{a}$ Jing Li ${ }^{a}{ }_{*}$

${ }^{a}$ Department of Chemistry and Chemical Biology, Rutgers University, 610 Taylor Road, Piscataway, New Jersey 08854, United States

${ }^{b}$ Advanced Light Source, Lawrence Berkeley National Laboratory, Berkeley California 94720, United States

\section{Graphic Abstract}

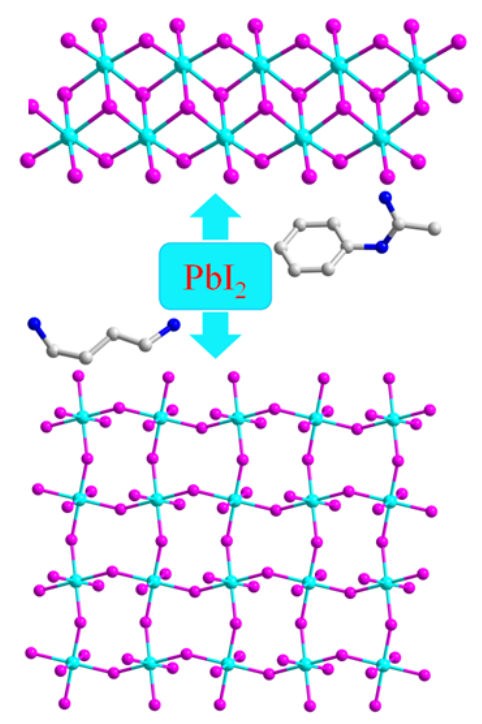

Two new hybrid lead halides built on one-dimensional edge-sharing double chains and twodimensional corner-sharing perovskite layers are synthesized and their structural and electronic properties are analyzed. 